Proc. Indian Acad. Sci. (Chem. Sci.), Vol. 112, No. 2, April 2000, pp. 127-136

(C) Indian Academy of Sciences

\title{
Effect of piperidones on hydrogen permeation and corrosion inhibition of mild steel in acidic solutions
}

\author{
S MURALIDHARAN, R CHANDRASEKAR and S V K IYER* \\ Central Electrochemical Research Institute, Karaikudi 630 006, India \\ e-mail: cecrik@cscecri.ren.nic.in
}

MS received 16 November 1999

\begin{abstract}
The influence of 3-methyl-2,6-diphenyl piperidin-4-one (MDPO) and 2phenyl decahydroquinoline-4-one (PDQO) synthesised in the laboratory on hydrogen permeation and corrosion inhibition of mild steel in $1 \mathrm{~N} \mathrm{H}_{2} \mathrm{SO}_{4}$ has been studied using weight loss and various electrochemical $\mathrm{AC}$ and $\mathrm{DC}$ corrosion-monitoring techniques. Both the compounds inhibit the corrosion of mild steel in $\mathrm{H}_{2} \mathrm{SO}_{4}$. Potentiodynamic polarisation studies clearly reveal that they behave predominantly as cathodic inhibitors. The extent of decrease in hydrogen permeation current through steel surfaces has been studied by the hydrogen electropermeation technique. Double layer capacitance $\left(C_{d l}\right)$ and charge transfer resistance $\left(R_{t}\right)$ values are derived from Nyquist plots obtained from AC impedance studies. The adsorption of these compounds on mild steel surfaces from $\mathrm{H}_{2} \mathrm{SO}_{4}$ obeys Temkin's adsorption isotherm.
\end{abstract}

Keywords. Corrosion inhibition; piperidones; hydrogen permeation; metal embrittlement; impedance measurements.

\section{Introduction}

The inhibiting influence of piperidine and cyclohexanone on the corrosion of copper in acidic solutions has already been studied ${ }^{1,2}$. This influence is attributed to the adsorption of these compounds through the $-\mathrm{NH}$ group in the case of piperidine and through the - $\mathrm{CO}$ group in the case of cyclohexanone. Piperidone contains both $-\mathrm{CO}$ and $-\mathrm{NH}$ groups. Further, in the case of piperidone, the cis form is the most stable form. In the present study, the influence of 3-methyl-2,6-diphenyl piperidin-4-one (MDPO) and 2-phenyl decahydroquinoline-4-one (PDQO) on the corrosion of mild steel in acidic solutions has been investigated, for getting an idea on the combined influence of $-\mathrm{CO}$ and $-\mathrm{NH}$ groups on the performance of these compounds as corrosion inhibitors.

\section{Experimental}

Mild steel specimens of the following composition, $\mathrm{C}=0.07 \%, \mathrm{P}=0.08 \%, \mathrm{Si}=$ nil, $\mathrm{S}=$ nil, $\mathrm{Mn}=0.34 \%$ and $\mathrm{Fe}=$ the remainder, and of size $5 \times 2 \times 0.025 \mathrm{~cm}$ were used for weight loss and hydrogen permeation studies. Mild steel cylindrical rods of the same composition embedded in araldite with an exposed area of $0.283 \mathrm{~cm}^{2}$ were used for potentiodynamic polarisation and AC impedance measurements.

*For correspondence 
Inhibitors were synthesised in the laboratory as per the procedures reported elsewhere ${ }^{3,4}$.

Both the inhibitors were preliminarily screened by the weight loss method described elsewhere ${ }^{5}$. Both cathodic and anodic polarisation curves were recorded potentiodynamically $\left(1 \mathrm{mV} \mathrm{s}^{-1}\right)$ using the corrosion measurement system BAS (Model: $100 \mathrm{~A}$ ) computerised electrochemical analyser (made in West Lafayette, Indiana) and PL-10 digital plotter (DMP-40 series, Houston Instrument Division). A platinum foil and $\mathrm{Hg} / \mathrm{Hg}_{2} \mathrm{SO}_{4} / 1 \mathrm{~N} \quad \mathrm{H}_{2} \mathrm{SO}_{4}$ electrode were used as auxiliary and reference electrodes respectively. The electrocapillary behaviour of these compounds was studied at $25 \pm 1^{\circ} \mathrm{C}$ using a capillary electrometer as described earlier ${ }^{6}$. Hydrogen permeation study was carried out using an adaptation of the modified Devanathan and Stachurski twocompartment cell as described earlier ${ }^{7,8}$. Double layer capacitance and charge transfer resistance values were obtained using AC impedance measurements as described earlier ${ }^{9}$.

\section{Results and discussion}

\subsection{Corrosion inhibition}

Table 1 gives values of inhibition efficiency for different concentrations of MDPO and PDQO in $1 \mathrm{~N} \mathrm{H}_{2} \mathrm{SO}_{4}$. It can be seen from this table that both these compounds inhibit the corrosion of mild steel in $1 \mathrm{~N} \mathrm{H}_{2} \mathrm{SO}_{4}$ solutions. The extent of inhibition is found to be more for MDPO than for PDQO. The inhibition of corrosion of mild steel by both these compounds can be explained as follows:

The extent of inhibition depends upon the nature and mode of adsorption of inhibitors on the metal surface. The adsorption is assumed to be a quasi-substitution process between the water molecules on the surface and the organic molecules. Both the compounds are adsorbed vertically with $-\mathrm{NH}$ group as the anchoring group and the $-\mathrm{CO}$ group projecting into the solution. The interaction of piperidones with the metal surface may occur either through the $-\mathrm{CO}$ or the $-\mathrm{NH}$ group but not through both of them, as they are in the (1, 4-para) position with respect to one another.

Table 1. Values of inhibition efficiency for different concentrations of MDPO and PDQO in $1 \mathrm{~N} \mathrm{H}_{2} \mathrm{SO}_{4}$.

\begin{tabular}{lc}
\hline Concentration $(\mathrm{mM})$ & Inhibition efficiency $(\%)$ \\
\hline$M D P O$ & \\
2 & $84 \cdot 8$ \\
5 & $87 \cdot 6$ \\
10 & $88 \cdot 2$ \\
15 & $89 \cdot 4$ \\
20 & $90 \cdot 3$ \\
& \\
$2 D Q O$ & \\
5 & $69 \cdot 6$ \\
10 & $78 \cdot 9$ \\
15 & $83 \cdot 6$ \\
20 & $84 \cdot 6$ \\
\hline
\end{tabular}


In MDPO and PDQO molecules, the electronegativity of atoms in the two groups favours $-\mathrm{NH}$ as the anchoring site. It is well-known that in piperidones, the lone pair of electrons in nitrogen is equatorial and the hydrogen attached to nitrogen is axial ${ }^{10}$. Therefore, when the adsorption of MDPO occurs, it takes place through the equatorial lone pairs. In this mode of adsorption, the high inhibition efficiency achieved with the cis form is interpreted in terms of screening of the metal surface by the bulky phenyl groups. The possible modes of adsorption of these compounds on the metal surface is shown in figure 1.

The greater inhibitive power of MDPO may be due to the presence of more $\pi$ electrons in the ring because of the presence of an extra phenyl group in the compound. The presence of an electron-releasing methyl group in the ring may also be responsible for the greater adsorption of this compound on the metal surface leading to greater inhibition. Hence MDPO inhibits the adsorption in $1 \mathrm{~N} \mathrm{H}_{2} \mathrm{SO}_{4}$ more than PDQO.

\subsection{Application of adsorption isotherm}

In the present study, values of surface coverage $(\theta)$ were evaluated using values of inhibition efficiency and capacitance as described earlier ${ }^{11}$. Different adsorption

a)

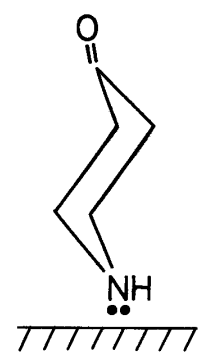

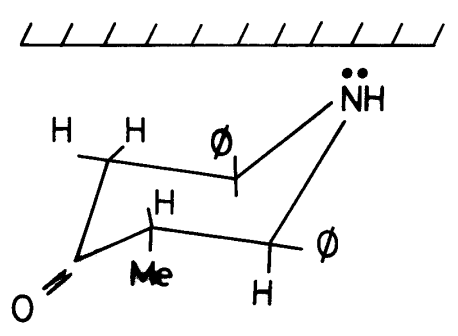

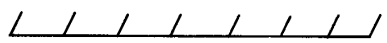

b)
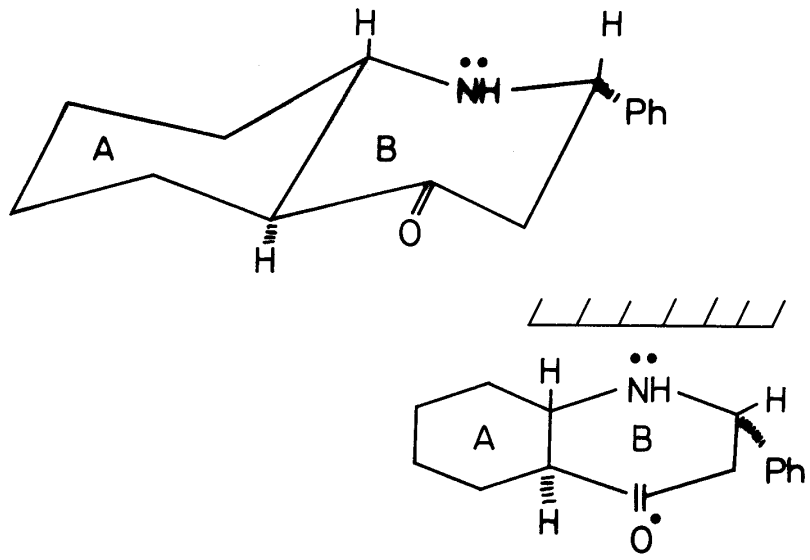

Figure 1. Possible modes of adsorption of (a) MDPO and (b) PDQO on the substrate. 
isotherms were tested for both the compounds. It can be seen from figure 2 that a straight line is obtained in both the cases when $\theta$ is plotted against $\log C$ proving thereby that the adsorption of these compounds on the surface of mild steel obeys Temkin's adsorption isotherm.

\subsection{Potentiodynamic polarisation studies}

Table 2 gives various corrosion kinetic parameters such as corrosion current $\left(I_{\text {corr }}\right)$, corrosion potential $\left(E_{\text {corr }}\right)$ and anodic and cathodic Tafel slopes $\left(b_{a}\right.$ and $\left.b_{c}\right)$ obtained from potentiodynamic polarisation curves. The influence of these compounds on the above kinetic parameters are discussed below.

It is found from table 2 that the addition of both the compounds shifts the $E_{\text {corr }}$ to less negative values. Values of corrosion current obtained by the extrapolation of Tafel plots for the corrosion of mild steel in $1 \mathrm{~N} \mathrm{H}_{2} \mathrm{SO}_{4}$ alone and in the presence of compounds under study bring out the fact that the decrease in corrosion current is greater in MDPO

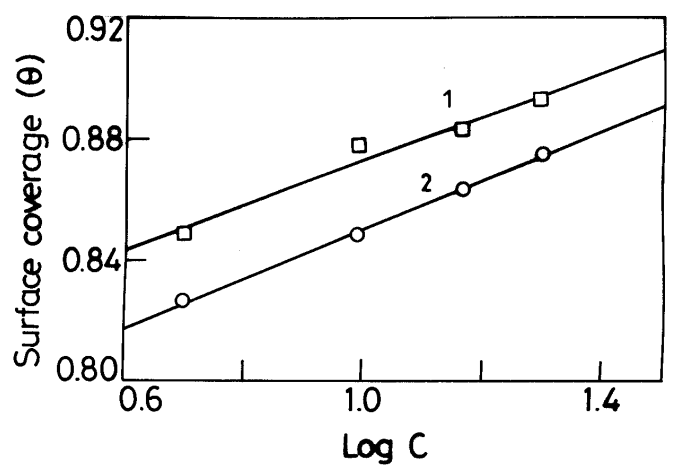

Figure 2. Temkin's isotherm plots for the adsorption of MDPO and PDQO on the surface of mild steel in $1 \mathrm{~N} \mathrm{H}_{2} \mathrm{SO}_{4}$. (1) MDPO, (2) PDQO.

Table 2. Potentiodynamic polarisation parameters for the corrosion of mild steel in $1 \mathrm{~N} \mathrm{H}_{2} \mathrm{SO}_{4}$ with and without inhibitors.

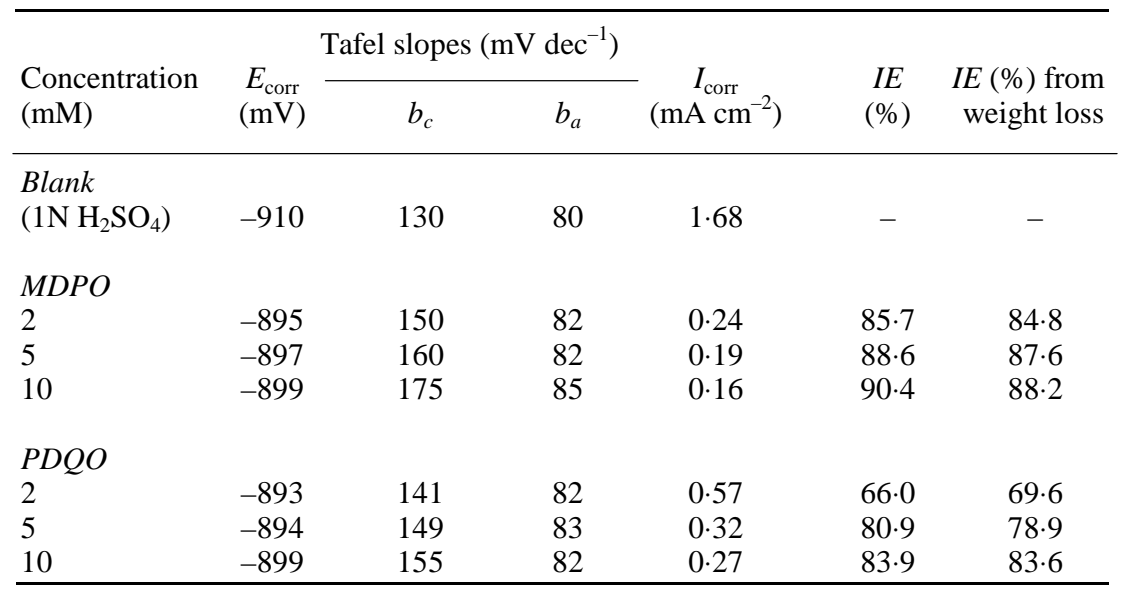


than in PDQO. This order agrees very well with that obtained for the corrosion inhibition efficiency.

Table 2 also gives values of inhibition efficiency obtained from weight loss measurements and from $I_{\text {corr }}$ values, in the absence and presence of compounds used in this study. Fairly good agreement has been noticed in a majority of cases.

In the absence of the compounds under study, the polarisation behaviour of mild steel in $1 \mathrm{~N} \mathrm{H}_{2} \mathrm{SO}_{4}$ shows an anodic Tafel slope of $80 \mathrm{mV}$ and a cathodic Tafel slope of $130 \mathrm{mV}$.

It has been observed that increase in the concentration of MDPO or PDQO increases the values of $b_{c}$. The increase is greater with MDPO. There is however only a very small increase in the values of $b_{a}$ with increase in concentration. Thus both these compounds function as cathodic inhibitors, by influencing the cathodic reaction of hydrogen evolution.

\subsection{Adsorption studies using capillary electrometer}

Electrocapillary curves for $1 \mathrm{~N} \mathrm{H}_{2} \mathrm{SO}_{4}$ in the presence of the compounds under study are plotted for obtaining a qualitative idea regarding the influence of different substituent groups or atoms present in these compounds on the extent of adsorption on the metal surface. This leads to an approximate correlation between the extent of adsorption and of corrosion inhibition by both the compounds.

Figure 3 shows the electrocapillary curves for $\mathrm{H}_{2} \mathrm{SO}_{4}$ in the presence of $5 \mathrm{mM}$ PDQO and MDPO. It is seen MDPO is adsorbed to a greater extent on the metal surface than PDQO and also that the adsorption is greater on the positively charged metal surface. The adsorption of MDPO on the metal surface can be explained in the following way.

Adsorption on the metal surface can be ascribed to the interaction between the $\pi$ electrons of the quinoline ring with the positively charged metal surface. The methyl group being nucleophilic leads to the release of more $\pi$-electrons, thereby favouring greater adsorption on the metal surface. Adsorption on the negatively charged metal surface may be due to the interaction between the cations formed in acidic solutions and the negatively charged metal surface.

In the case of PDQO also, the adsorption characteristics can be explained in a similar way. The order of extent of adsorption and corrosion inhibition efficiency follows the same trend in $\mathrm{H}_{2} \mathrm{SO}_{4}$ solutions,

$$
\text { MDPO (87.6\%) > PDQO (78.9\%). }
$$

Thus definite correlation exists between the extent of adsorption and the efficiency of corrosion inhibition.

\subsection{Hydrogen permeation measurements}

Hydrogen can enter into the metal during various industrial operations like melting, heat treatment, or pickling and electrochemical processes such as cathodic cleaning and electrolytic machining. Of the various sources of entry of hydrogen into the metal, pickling is one of the basic steps in electroplating processes in which mineral acids are used for the removal of rust and scale. The following are the main reactions in acidic solutions 


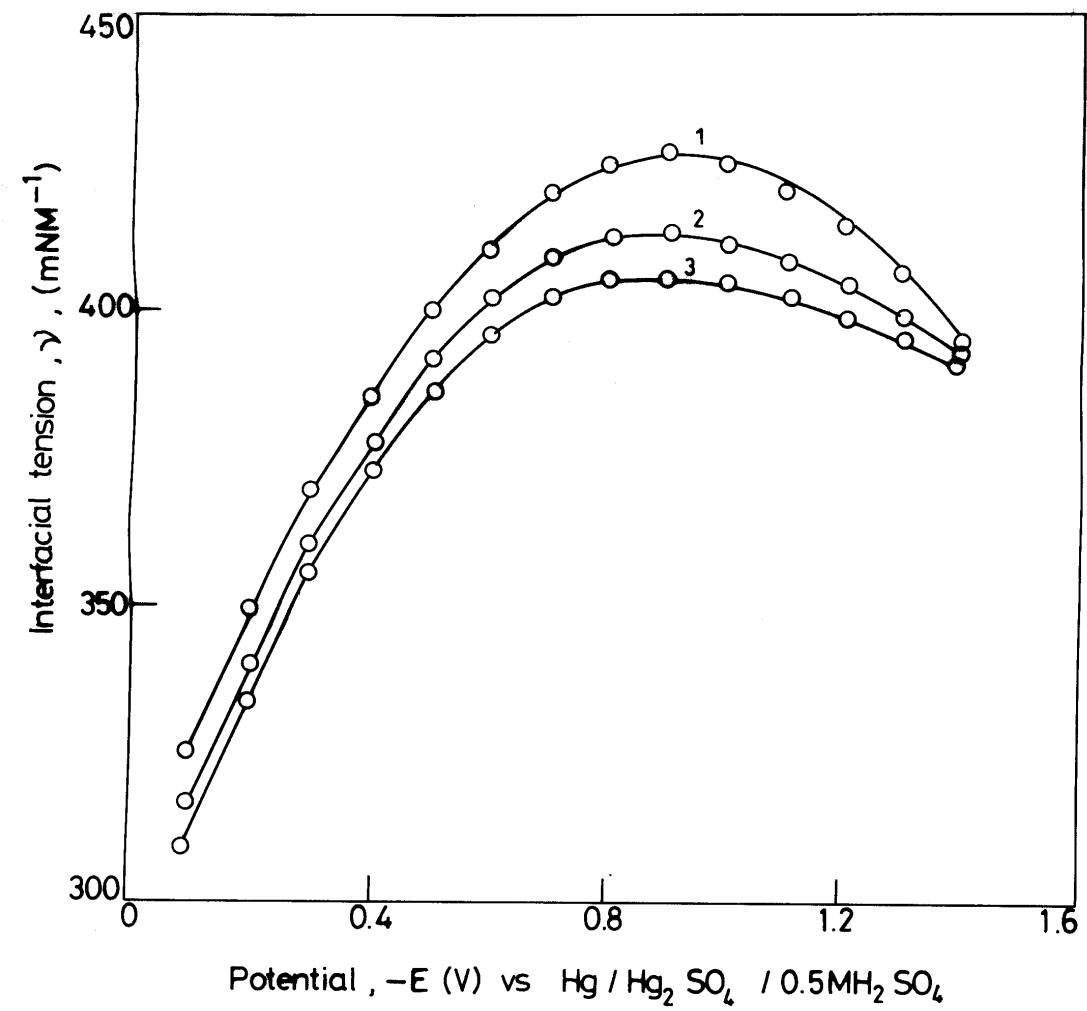

Figure 3. Electrocapillary curves for $1 \mathrm{~N} \mathrm{H}_{2} \mathrm{SO}_{4}$ in the presence of $5 \mathrm{mM}$ of MDPO and PDQO. (1) $1 \mathrm{~N} \mathrm{H}_{2} \mathrm{SO}_{4}$, (2) $1 \mathrm{~N} \mathrm{H}_{2} \mathrm{SO}_{4}+5 \mathrm{mM} \mathrm{MDPO}$, (3) $1 \mathrm{~N} \mathrm{H}_{2} \mathrm{SO}_{4}+5 \mathrm{mM}$ PDQO.

$$
\mathrm{M}+\mathrm{H}_{3} \mathrm{O}^{+}+e^{-} \rightarrow \mathrm{H}_{2} \mathrm{O}+\mathrm{MH}_{\mathrm{ads}}
$$

where $M$ is the cathodic metal surface. This discharge step is followed by either

$$
\mathrm{MH}_{\mathrm{ads}}+\mathrm{MH}_{\mathrm{ads}} \rightarrow 2 \mathrm{M}+\mathrm{H}_{2},
$$

(or)

$$
\begin{aligned}
\mathrm{MH}_{\mathrm{ads}}+\mathrm{H}_{3} \mathrm{O}^{+}+e^{-} \rightarrow \underset{\text { (electrochemical desorption) }}{\mathrm{M}}+\mathrm{H}_{2} \mathrm{O}+\mathrm{H}_{2} .
\end{aligned}
$$

A part of the atomic hydrogen liberated during the pickling process enters the metal, and the remainder is evolved as hydrogen gas. Organic compounds are generally added to pickling baths in order to minimise the base metal attack and limit the hydrogen liberated. However, the fraction of hydrogen atoms that enters the metal produces some detrimental effects $^{12}$ on the mechanical properties of iron/steel, such as reduction in ductility, lowering of fracture stress and loss in mechanical strength leading to embrittlement. This phenomenon is also called 'delayed failure'. It has been already pointed out that hydrogen permeation current measurement, under pickling conditions, can be a useful tool for 
evaluating inhibitors from the point of view of predicting the extent of hydrogen embrittlement. A similar suggestion has been made with regard to the screening of additional agents employed in electroplating baths for their capacity to decrease hydrogen intake $^{13}$.

In the present study the hydrogen permeation currents are recorded in $\mathrm{H}_{2} \mathrm{SO}_{4}$ in the absence and presence of inhibitors. This study has been taken up with an idea of screening the inhibitors with regard to their effectiveness on the reduction of hydrogen uptake.

Figure 4 shows the variation of permeation current vs time for mild steel in $1 \mathrm{~N} \mathrm{H}_{2} \mathrm{SO}_{4}$ in the presence of MDPO and PDQO (5 mM).

It is found from figure 4 that both these compounds bring down the permeation current to the extent of 50\% and that MDPO performs better than PDQO. The corrosion inhibition efficiency of these compounds in $1 \mathrm{~N}_{2} \mathrm{SO}_{4}$ follows the same order.

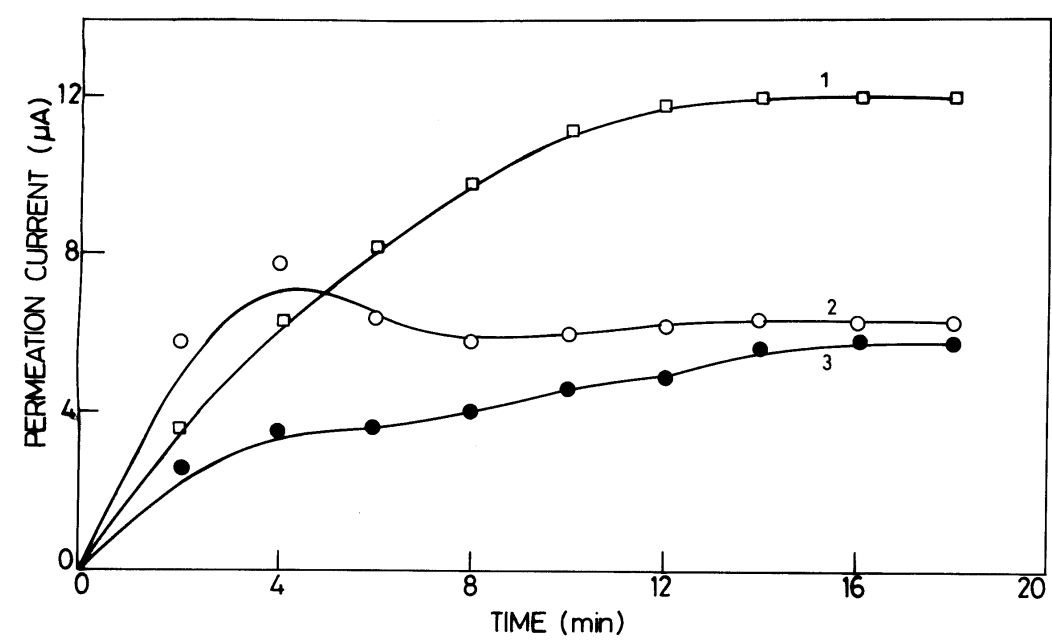

Figure 4. Hydrogen permeation vs. time curves for mild steel in $1 \mathrm{~N}_{2} \mathrm{SO}_{4}$ containing MDPO and PDQO. (1) $1 \mathrm{~N} \mathrm{H}_{2} \mathrm{SO}_{4}$, (2) $1 \mathrm{~N} \mathrm{H}_{2} \mathrm{SO}_{4}+5 \mathrm{mM}$ PDQO, (3) $1 \mathrm{~N}$ $\mathrm{H}_{2} \mathrm{SO}_{4}+5 \mathrm{mM}$ MDPO.

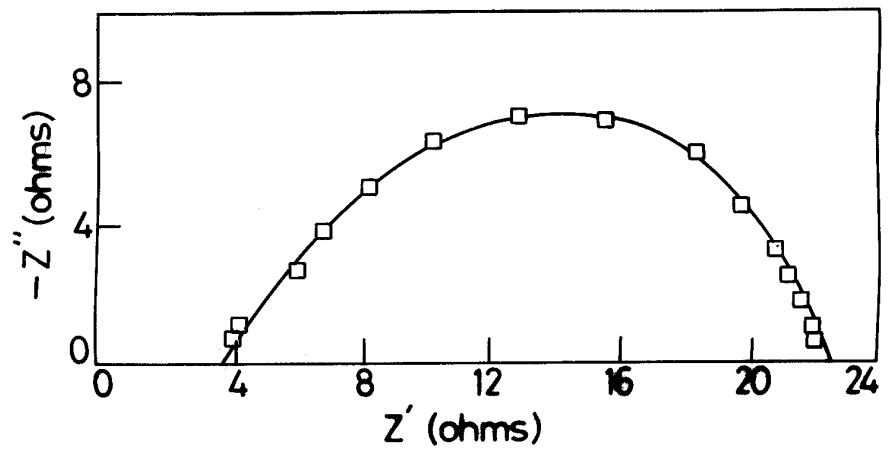

Figure 5. Impedance diagram for mild steel in $1 \mathrm{~N} \mathrm{H}_{2} \mathrm{SO}_{4}$. 


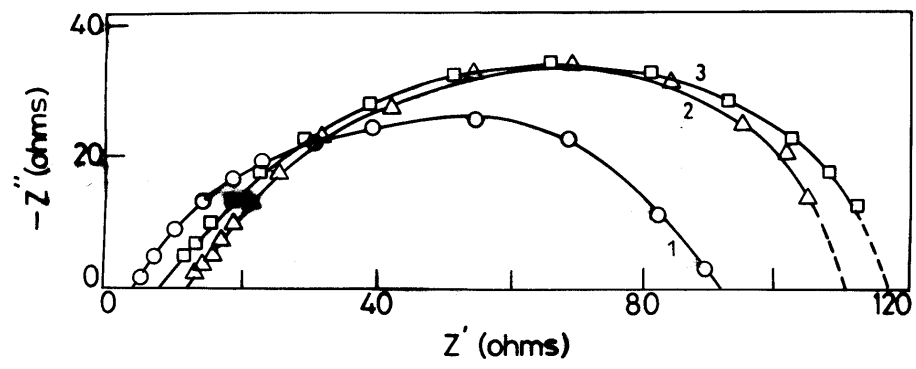

(a)

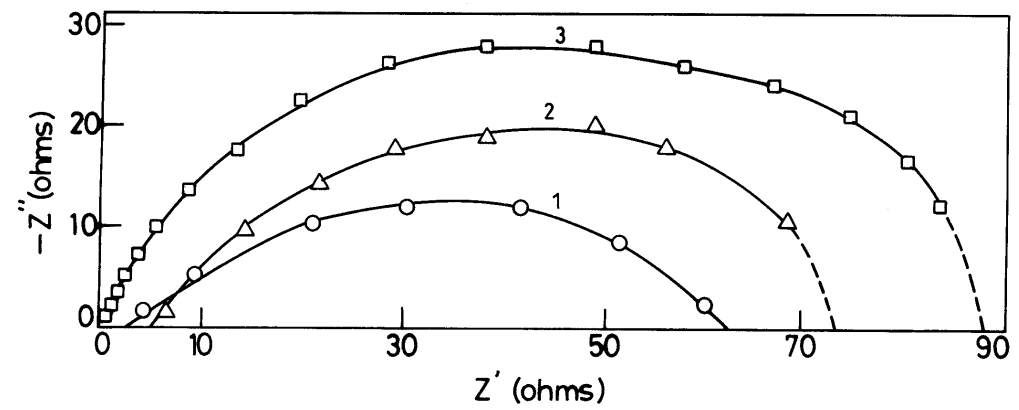

(b)

Figure 6. (a) Impedance diagrams for mild steel in $1 \mathrm{~N} \mathrm{H}_{2} \mathrm{SO}_{4}$ containing different concentrations of MDPO. (1) $1 \mathrm{~N} \mathrm{H}_{2} \mathrm{SO}_{4}+2 \mathrm{mM} \mathrm{MDPO}$, (2) $1 \mathrm{~N} \mathrm{H}_{2} \mathrm{SO}_{4}+5 \mathrm{mM}$ MDPO, (3) $1 \mathrm{~N} \mathrm{H}_{2} \mathrm{SO}_{4}+10 \mathrm{mM}$ MDPO. (b) Impedance diagrams for mild steel in $1 \mathrm{~N}$ $\mathrm{H}_{2} \mathrm{SO}_{4}$ containing different concentrations of PDQO. (1) $1 \mathrm{~N} \mathrm{H}_{2} \mathrm{SO}_{4}+2 \mathrm{mM}$ PDQO, (2) $1 \mathrm{~N} \mathrm{H}_{2} \mathrm{SO}_{4}+5 \mathrm{mM}$ PDQO, (3) $1 \mathrm{~N} \mathrm{H}_{2} \mathrm{SO}_{4}+10 \mathrm{mM}$ PDQO.

Thus a definite correlation exists between the corrosion inhibition efficiency and the extent of reduction in the permeation current of these compounds. It is a well-known fact that the higher the cathodic Tafel slope in the presence of an inhibiting compound, the lesser is the corrosion and hydrogen intake by the metal. An increase in the cathodic Tafel slope leads to increase in the energy barrier for proton discharge and decrease in the evolution of hydrogen. This in turn leads to lower permeation of hydrogen through the metal. In this regard MDPO which has the more cathodic Tafel slope performs better than PDQO.

\subsection{Impedance measurements}

Impedance diagrams obtained for the frequency $60 \mathrm{kHz}$ to $\mathrm{mHz}$ range at the open circuit potential for mild steel in $1 \mathrm{~N} \mathrm{H}_{2} \mathrm{SO}_{4}$, in the presence and absence of different compounds under study are shown in figures 5 and 6 . It is seen from these figures that the impedance diagrams in both the cases are not perfect semicircles. This difference has been attributed to the frequency dispersion ${ }^{14}$.

Impedance parameters derived from Nyquist plots are given in table 3. It is observed that the value of charge transfer resistance $\left(R_{t}\right)$ increases with increase in the concentration of the inhibitors and that this in turn leads to a decrease in $I_{\text {corr }}$ for mild steel in the acidic solution. As impedance diagrams for solutions examined have almost a semicircular appearance, it indicates that the corrosion of steel is mainly controlled by a 
Table 3. Impedance parameters for the corrosion of mild steel in $1 \mathrm{~N} \mathrm{H}_{2} \mathrm{SO}_{4}$ in the presence of different concentrations of inhibitors.

\begin{tabular}{lcccc}
\hline Concentration & $\begin{array}{c}R_{t} \\
\left(\mathrm{ohm} \mathrm{cm}^{2}\right)\end{array}$ & $\begin{array}{c}C_{\mathrm{dl}} \\
\left(\mu \mathrm{F} \mathrm{cm}^{-2}\right)\end{array}$ & $\begin{array}{c}I_{\text {corr }} \\
\left(\mathrm{mA} \mathrm{cm}^{-2}\right)\end{array}$ & $\begin{array}{c}I E \\
(\%)\end{array}$ \\
\hline Blank & 6.36 & 183.2 & 3.38 & - \\
MDPO & & & & \\
2 & 64.2 & 105.6 & 0.45 & 86.6 \\
5 & 73.3 & 94.4 & 0.41 & 87.7 \\
10 & 74.1 & 92.5 & 0.39 & 88.4 \\
& & & & \\
2 & & & & \\
5 & 62.2 & 107.2 & 0.85 & 74.7 \\
10 & 75.4 & 96.8 & 0.51 & 84.8 \\
\hline
\end{tabular}

charge transfer process. Double layer capacitance values $\left(C_{d l}\right)$ decreases as the concentration of inhibitor increases which indicates the adsorption of the inhibitor on the metal surface.

Both the compounds act as inhibitors as observed from values of $R_{t}, C_{d l}$ and $I_{\text {corr }}$ from table 3. Among the two, MDPO performs better in $1 \mathrm{~N}_{2} \mathrm{SO}_{4}$ by enhancing the value of $R_{t}$ to a greater extent than PDQO and also by bringing down the $C_{d l}$ and $I_{\text {corr }}$ values to a greater extent than PDQO.

\section{Conclusions}

The following main conclusions are drawn from the present study.

(1) Both MDPO and PDQO inhibit the corrosion of mild steel in $1 \mathrm{~N}_{2} \mathrm{SO}_{4}$, but the former is found to be more effective.

(2) Both compounds behave as cathodic inhibitors.

(3) Adsorption of these compounds on the surface of mild steel from $1 \mathrm{~N} \mathrm{H}_{2} \mathrm{SO}_{4}$ obeys Temkin's adsorption isotherm.

(4) Both the compounds bring about a reduction in permeation current through mild steel in $\mathrm{H}_{2} \mathrm{SO}_{4}$ but MDPO is more effective.

(5) Reduction in the values of $I_{\text {corr }}$ and $C_{d l}$ in the presence of these compounds brings out the better performance of MDPO.

\section{Acknowledgement}

The authors thank Dr M Raghavan for encouragement.

\section{References}

1. Khitrov V A, Zadorozhnyi V P, Smolyaninov I S, Zhukova G P, Dugin N A and Konyaev B Ya 1964 Khim. Prom. 4 307; 1965 Chem. Abstr. 61 6698e

2. Levin I A and Solomon E M 1963 Khim. Prom. 1 69; 1963 Chem. Abstr. 593594 
3. Ravindran T, Jayaraman R, Murray R W and Singh M 1991 J. Org. Chem. 564833

4. Baliah V and Natarajan A 1981 Indian J. Chem. B20 830

5. Muralidharan S, Ramesh Babu B, Venkatakrishna Iyer S and Rengamani S $1996 \mathrm{~J}$. Appl. Electrochem. 26291

6. Devanathan M A V and Peries P 1954 Trans. Faraday Soc. 501236

7. Devanathan M A V and Stachurski 1962 Proc. R. Soc. London A270 90

8. Muralidharan S, Quraishi M A and Venkatakrishna Iyer S 1995 Corros. Sci. 371739

9. Muralidharan S, Phani K L N, Pitchumani S, Ravichandran S and Iyer S V K 1995 J. Electrochem. Soc. 1421478

10. Aroney M and Lefevre R J W 1958 J. Chem. Soc. 3002

11. Rengamani S, Muralidharan S, Anbukulandainathan M and Venkatakrishna Iyer S $1994 J$. Appl. Electrochem. 24355

12. Subramanyan N, Rangarajan S K, Balakrishnan K, Venkatakrishna Iyer S, Venkatesan S and Sathianandham B 1970 Proc. 3rd Euro. Symp. On Corrosion Inhibition Ferrara, Italy, NS, Sez. V, p. 592

13. Srinivasan K N and Venkatakrishna Iyer 1989 Trans. Soc. Adv. Electrochem. Sci. Technol. 24 205

14. Juttner K 1990 Electrochim. Acta 351502 